\title{
The Role of Sleep in Motor Learning
}

\section{Rajprasad Loganathan ${ }^{1,2}$}

${ }^{1}$ Department of Physical Therapy and Rehabilitation Science, The University of Kansas Medical Center, 3901 Rainbow Blvd, Kansas City, Kansas $66160,{ }^{2}$ Current Affiliation Department of Cell Biology, The Johns Hopkins University, 725 N.Wolfe St, Baltimore, Maryland 21205, USA

Email: rlogana2@jhmi.edu

\begin{abstract}
Numerous factors affect motor learning, and its subsequent consolidation into effortlessly retrievable motor memories. Evidence from sleep research suggests a role for sleep in motor learning and motor memory consolidation. Optimal motor performance on a recently learned task is facilitated by sleepmediated consolidation of motor memories. Yet, sleep independent motor memory consolidation occurs for few tasks and do not appear to hamper performance. Growing evidence, however, is suggestive of a facilitative role for sleep in motor learning. Meanwhile the mechanisms underlying sleepmediated consolidation of motor memories are not clear, and the possible relevance of hippocampus to motor memory in the context of sleep-state awaits exploration.
\end{abstract}

Keywords: hippocampus, memory consolidation, motor learning, neocortex, sleep

\section{Introduction}

Motor learning is the central process that shapes our behavior. Behavior is the result of a sensorial perception that interacts with memories of previous experiences and with the individual's emotional states among several other factors. Despite its complexity, behavior manifests as the total movements made by the intact animal (Tinbergen, 1952). Following this broad perspective of behavior, motor learning is the ability to enrich behavior on a relatively permanent timescale based on experience. Motor learning is not a unitary process, and therefore requires multiple neuroanatomical substrates (Halsband and Freund, 1993). Though it utilizes the mechanisms of working memory (Ungerleider et al., 2002; Doyon et al., 2003; Willingham, 1998), for most part the knowledge about "how to perform on a task" is acquired implicitly (Pascual-Leone et al., 1994). Following acquisition, the information on "how to perform?" is consolidated and stored for subsequent retrieval in a time dependent fashion (Ungerleider et al., 2002). The memory built in this fashion is "procedural" since it houses information about procedures rather than facts (Hikosaka et al., 1999).

Multiple neural substrates participate at various stages of motor learning and motor memory consolidation (Willingham, 1998; Halsband and Freund, 1993; Doyon et al.2003; Ungerleider et al., 2002). The proposed sites of motor memory consolidation include the cerebellum (Shadmehr and Holcomb, 1997; Imamizu et al., 2000), striatum (Ungerleider et al., 2002; Doyon et al., 2003), motor cortex (Wise et al., 1998; Karni, 1996; Georgopoulos, 2000), and prefrontal cortex (Fuster, 2000) among others. Various factors affect motor learning at different stages of the learning process. These are genes (Fox et al., 1996), practice (Petersen et al., 1998; Lee et al., 1991; Higgins, 1991), feedback (Kawashima et al., 2000; Todorov et al., 1997), reinforcement or reward (Thut et al., 1997; Schultz et al., 1997), observation (Heyes and Foster, 2002), force (Decker and Rogers, 1973; Minden, 1972), strategical knowledge (Goode et al., 1998), mental imagery neuroanatomical substrates underlying learning dependent changes in the brain (Doyon et al., 2003). The cortico-striatal system functions as 
the consolidative apparatus for motor sequence learning while the cortico-cerebellar system performs the same role for motor adaptation learning. This dichotomy in motor skill learning based on neural substrates has the following advantages: 1) It allows us to manipulate the systems and probe for predicted effects and 2) It offers the opportunity to dissect the effects of various factors (like sleep) on motor learning due to the advantage of localization of consolidative mechanisms. Meanwhile, a broader scheme of motor learning would also include other forms of motor learning that occur in conditional motor learning (Passingham, 1988), reflex adaptation (Lisberger, 1988), and conditioned reflex (McCormick and Thompson, 1984) paradigms. Studies that investigate the relationship between sleep and motor learning have taken the broad perspective, therefore, testing experimental paradigms that are sensitive to diverse forms of motor learning (Table 1).

\section{The sleep-memory consolidation hypothesis}

The function of sleep is not clear, though it has been linked to multiple physiological processes (Rechtschaffen et al., 1989) including memory consolidation (Maquet, 2001; Kavanau, 1997). Both non-rapid eye movement sleep (NREM sleep) and rapid eye movement sleep (REM sleep) have been implicated in memory consolidation (Maquet, 2001; Smith, 2001). NREM sleep deprivation impairs consolidation of declarative memory (Plihal and Born, 1999), whereas REM sleep deprivation results in the failure of procedural memory consolidation (Smith, 1995; Plihal and Born, 1999). With respect to motor learning that belongs to a subset of procedural (implicit) learning processes, evidence has accumulated over the past few years on its facilitation by sleep.

\section{Consolidation of motor sequence learning requires sleep}

As mentioned earlier, motor sequence learning appears to occur on the cortico-striatal substrates (Doyon et al., 2003).The tasks commonly employed to study motor sequence learning are the serial reaction time task (SRTT) (Nissen and Bullemer, 1987), sequential finger to thumb opposition task (SFTT) (Fischer et al., 2002), and pursuit rotor task (PRT) (Smith and MacNeill, 1994).The performance on these tasks sets a relatively higher demand on the motor systems than cognitive or perceptual systems thereby rendering them suitable for motor sequence learning paradigms (Table 1).

The consolidation of motor memory for SRTT is facilitated by sleep. In a positron emission tomography (PET) study, Maquet et al (Maquet et al., 2000) measured the changes of regional blood flow in subjects who slept following acquisition of a sequence on the SRTT paradigm. Sleep-state reactivation of areas that participated in task acquisition indicated ongoing local metabolic activity (indicating neuronal activity) during REM sleep. That the blood flow patterns were specific to motor memory consolidation was further supported by the improved performance of subjects trained on the task, compared to non-trained subjects, on post-sleep testing. In a similar study, Laureys et al (Laureys et al., 2001) showed that functional connectivity changes occur in the cortical regions during REM sleep in subjects trained on SRTT. Increased cerebral functional connectivity of specific structures during sleep in subjects trained on SRTT was suggested to be due to reprocessing and consolidation of motor memory traces. Optimization of a specific motor memory network during sleep was further supported by the performance gain by trained subjects on the following day compared to untrained subjects.

Consolidation of motor memory for SFTT is also facilitated by sleep. Walker et al (Walker et al., 2002), in their elegant study, presented evidence that stage 2 NREM sleep but not simple passage of time, circadian factors, task repetition, and hand rest facilitate performance on motor skill learning. Fisher et al showed that the internal model formed during sleep is 
specific only for the learned sequence of SFTT (Fischer et al., 2002), and accuracy is sensitive to sleep-state consolidation rather than speed. Also, daytime wakefulness proved to be less deteriorative to motor memory consolidation than nighttime wakefulness. In this study, however, REM sleep duration rather than stage2 NREM sleep correlated with improved motor performance. Finally, improved performance on PRT is also facilitated by stage 2 NREM sleep (Smith and MacNeill, 1994; Forest and Godbout, 2000).

\section{Not all forms of motor learning require sleep for consolidation}

Motor skill adaptation learning occurs as subjects learn to fine-tune their motor control processes while adapting to kinetic perturbations. A primary lab version of this task utilizes a two joint robotic manipulandum that is held by the subject while reaching for a goal under various force fields (Shadmehr and Brashers-Krug, 1997). As the subject masters control over imposed perturbations during practice sets, the trajectory becomes straighter indicating the formation of an internal model for the particular force field. Internal model formation for a particular force field is confirmed by imposing a null field during the acquisition phase (catch trial) during which the subject shows "after effects", i.e., a movement trajectory that is a mirror image of the distorted trials induced by initial exposure to the forcefield (Donchin et al., 2002). The neural substrates of motor adaptation learning are the cortico-cerebello-cortical loops (Doyon et al., 2003). Consolidation of motor memory distinct for a motor adaptation learning task occurs as early as four hours in human subjects (BrashersKrug et al., 1996). The study by Donchin et al (Donchin et al., 2002) reported the effects of various drugs that affect learning dependent cortical plasticity on a motor skill adaptation learning task (point-to-point reaching movement with a robotic arm under a preprogrammed force field) in humans. A sleep deprivation group was also included in the study to control for the drug side effects such as drowsiness and jitters. No deficit in performance was reported for the sleep deprivation group on this form of motor learning. Also interesting, is the fact that sleep deprivation did not affect learning on a second task (under a different force field) in this group as shown by the absence of difference from controls that learned the same task after sleep. These findings show that initial acquisition and consolidation of adaptations for a motor learning task could occur without the influence of sleep. However, this may not be evidence that motor learning paradigms utilizing the cerebellar substrate for task acquisition and performance are sleep independent for performance. Learning and memory mechanisms of classical eyeblink conditioning, a paradigm that is included under a broader perspective of cerebellar motor learning (McCormick and Thompson, 1984), appear to be sensitive to REM sleep deprivation (Ohno et al., 2002).

\section{Consolidation of other forms of motor learning also benefits from sleep}

Sleep studies have also examined the effects of sleep on atypical motor learning tasks that demand relatively more resources from cognitive or perceptual learning domains (Smith, 2001) for task acquisition and performance. Though motor learning occurs in these cognito-motor and perceptuo-motor tasks, performance on these tasks rely primarily on working memory and/or perceptual systems (Table 1). Cognito-motor and perceptuo-motor learning occurs by recruiting structures of prefrontal and parieto-temporo-occipital areas respectively (Fuster, 2000; Maquet et al., 2003). Sleep dependency on performance in these tasks suggests a role for sleep-state consolidation of learned information. For example, performance on the tower of Hanoi task deteriorates after sleep deprivation (Smith, 1995). Post-learning sleep facilitates consolidation of the internal model for a visuomotor task (Maquet et al., 2003). In 
addition, sleep appears to play an interesting role in improving the performance on complex movement sequences learned in trampolining (Buchegger et al., 1991; Buchegger and MeierKoll, 1988).

\section{Mechanisms underlying sleep-mediated consolidation of motor memories are not clear}

With the proposal of multiple forms and sites of motor learning, and the possibility of distributed networks of motor memory consolidation (Shadmehr and Holcomb, 1997; Ungerleider et al., 2002), the systems level solution to the motor information processing problem remains elusive. Nevertheless, the facilitative role of the yet to be revealed mechanisms of motor memory consolidation by brain states adds another biologically interesting dimension to this problem. While sleep appears to influence the consolidation of a variety of motor learning forms, the information processing mechanisms underlying sleep-state consolidation are not clear. Meanwhile studies directed at addressing the possibility of information processing during sleep using other forms of associative learning paradigms have yielded encouraging results that could guide the approach on specific problems of motor memory consolidation. A series of experiments utilizing neuronal recording from networks mediating adaptive plasticity on a classical conditioning paradigm in rats (Hennevin et al., 1995), revealed that (a) learning systems are operational during REM sleep (b) associative learning at the neuronal level could be induced during REM sleep (c) expression of this "sleep learning" during wakefulness is possible and (d) associative learning that occurs at the neuronal level is testable at the behavioral level. Overall, these results are evidence that learning processes are operational during sleep-state. Another line of evidence that complements these results is the sleep-state studies on the neurons of hippocampus (Wilson and McNaughton, 1994; Poe et al., 2000; Louie and Wilson, 2001).
Hippocampus as a functional model of offline memory consolidation

Since the specific mechanisms underlying sleepmediated consolidation of motor memories are not known, a speculative discussion on the possible cellular mechanisms might be presented based on the evidence from neural signaling studies of learning and memory on small systems of neurons in invertebrates and the mammalian hippocampus. These results demonstrate that some of the molecular and cellular events underlying memory consolidation are similar for both implicit and explicit learning (Kandel, 2000). Furthermore, inspired by the theoretical predictions favoring the possibility of memory consolidation during "offline" brain states in the archicortex (Marr, 1971), studies have focused on hippocampal neurons for the possibility of sleep-state information processing. The sleep-state studies on hippocampus provide a model for studying similar "offline" information processing systems in the mammalian brain including motor memory systems. Alternatively, results also suggest the hippocampus as a memory consolidation switch that toggles - depending on the brain state - perhaps to bind motor information with spatial information during sleep. It is at this juncture of sleep, the neural network in hippocampus becomes an interesting subject for discussion on memory consolidation relevant to motor learning.

The hippocampus contains neurons (place cells) that code for allocentric space during spatial translocation in animals (O'Keefe, 1976) and topographical exploration in humans (Maguire et al., 1996). For this reason, the hippocampus is considered to be the locus of the cognitive map (Maguire et al., 1999). In addition, the hippocampal neurons process non-spatial information as well (Wood et al., 2000; Wood et al., 1999; Vanderwolf, 2001). In rats, the hippocampal place cells are activated only during spatial translocation accompanied by voluntary movements (Vanderwolf, 1969; Vanderwolf, 2001). These results indicate the 
importance of hippocampus as a motor information processing network, albeit under different contexts from those served by the primary motor structures like the basal ganglia and cerebellum. Findings on the role of hippocampus in sensorimotor integration (Tesche and Karhu, 1999) and evidence for movement related action potentials from human hippocampal units (Halgren, 1991) bolster the notion of an integrative and / or interactive supramodal hippocampal network, binding motor and non-motor information to adaptively consolidate retrievable memories that benefit performance.

Sleep-state ensemble recordings from neural networks participating in task learning during wakefulness support the role for large scale modular activity of memory circuits during sleep. In one such study, Wilson and McNaughton (Wilson and McNaughton, 1994) reported that correlated pairs of hippocampal CA1 neurons that activated during daytime learning on a maze running task were reactivated again during NREM sleep following the learning episode, thereby expressing spontaneous retrieval of recently stored activity patterns. In another study, Louie and Wilson (Louie and Wilson, 2001) reported recordings of longer time scale theta waves from the CA1 neurons of rats learning a spatial locomotor task during wakefulness. Same neural activity was replayed at a lower frequency during post learning REM sleep, suggesting the importance of sleep-state activity in information processing. The sharp waves or ripples $(140-200 \mathrm{~Hz})$ recorded from hippocampus during NREM sleep seems to orchestrate the replay of hippocampal information back to neocortical areas of memory storage (Siapas and Wilson, 1998).

Meanwhile during REM sleep, multimodal information from association areas might flow into the hippocampus (Hennevin et al., 1995) in phase with the theta rhythm (Louie and Wilson, 2001) setting the stage for a two-phase process of memory consolidation (Lorincz and Buzsaki, 2000).The theta rhythm (4 to $7 \mathrm{~Hz}$ ) is recordable both during exploratory movements and REM sleep in rats. The neural activity during sleep following a novel experience occurs in phase with the theta rhythm in the hippocampus, a condition known to induce long term potentiation (LTP) (Maquet, 2001). LTP refers to the localized changes in active synapses that consolidate memory by increasing synaptic potentiation (Bliss and Lomo, 1973), initially demonstrated in the hippocampal formation, and later shown in other areas including the motor cortex (Iriki et al., 1989). Yet, within the limits of available evidence, current biological models on the operations of hippocampal memory storage network during "offline" brain states prove to be inadequate in establishing a direct role for sleep in memory consolidation (Maquet, 2001). Nevertheless, these models provide a working framework to extend our understanding of memory consolidation under differing brain states.

\section{Neocortical mechanisms of sleep-state memory consolidation}

The neocortex has also been the focus of investigations relating sleep and memory processes in addition to studies implicating archicortex. This is due to the abundance of information flow and the interdependence of information processing between regions of the neocortex and archicortex for the consolidation of multiple forms of memory. The neocortical circuits established by hippocampus-neocortex interactions during NREM sleep subsequently engage the hippocampus during REM sleep (Louie and Wilson, 2001). Moreover, the neural correlation state for a given neocorticalhippocampal cell pair established on a maze learning task tends to be preserved during during subsequent sleep (Qin et al., 1997).

The notion that neocortex might be involved in procedural memory consolidation during sleep has been the direct result of brain imaging studies already discussed (Maquet et al., 2000). Synchronized thalamocortical fast oscillations 
indicative of consolidative changes have been reported in cats during post learning sleep (Amzica et al., 1997) substantiating the role of neocortex in memory consolidation. The cortical role in memory consolidation during sleep is also evident from the reports of expression of immediate early genes (IEGs), the signaling substrates (third messengers) that mediate a variety of cellular responses within minutes of information transfer from the first messengers. In the neurons of hippocampus, IEGs are induced in response to a variety of stimuli (Morgan and Curran, 1989). A novel multimodal waking experience in an enriched environment, results in upregulation of Zif-268, one of the IEGs implicated in learning induced neural plasticity in cortex and hippocampus in rats. The post experience expression of this gene was detected during REM sleep (Ribeiro et al., 1999), indicating a favorable stage for consolidative changes set by the post learning sleep-state.

\section{An open question}

The above discussion leads to an open question; 'How does procedural learning occur in the absence of hippocampus?' as shown by numerous reports (Squire, 1992). As a speculative scenario, the possibility of two operating systems for the generation of procedural engrams might be considered. The first system might be a sleep-state hybrid network that overlaps or functions in concert with declarative memory systems like the hippocampal system to enhance the binding of items in both declarative and non-declarative domains that is required for successful task performance in motor learning paradigms like the motor sequence learning (Schendan et al., 2003) and forms of conditional oculomotor and skeletomotor learning that also require the hippocampus for optimal learning and performance (Wise, 1996). This system might also influence the performance on variants of conditioned reflex paradigms that require hippocampus for successful consolidation
(Moyer et al., 1990; McGlinchey-Berroth et al., 1997).

Meanwhile, the second system may process information in parallel with the former but still operate optimally under sleep independent brain states to consolidate motor memories that are required for the construction of internal models for performance in tasks that involve motor adaptation learning which appear to be insensitive to sleep deprivation for successful performance (Shadmehr and Holcomb, 1997; Shadmehr and Brashers-Krug, 1997; Donchin et al., 2002; Brashers-Krug et al., 1996). Adaptedness in the form of multiple crude systems for procedural memory consolidation might have been favored by natural selection to a single precise system, thereby enhancing economy to procedural information processing networks due to their demand for processing an abundance of information during the lifetime of the individual similar to that of visual systems (Swindale, 1986). The resulting redundancy might then enhance the precision of simple and complex movements both in biological (Kovac et al., 1983) and artificial neural systems (Medler and Dawson, 1994). Under these circumstances, whether the redundant procedural information processing networks are state dependent remains another interesting question. However this idea needs to be explored further as a possibility to explain the disparity in the sensitivity of different forms of motor learning to sleep-state consolidation.

Evidence supports a role for sleep in consolidation of procedural memories. Motor sequence learning, cognito-motor learning, and perceptuo-motor learning benefit from sleep while motor adaptation learning is unhampered without the benefits of sleep. Whether the role of sleep is causal or coincidental in motor learning remains to be addressed. Another aspect that remains to be clarified is the difference in sensitivity of procedural material to particular phases of sleep. Both REM sleep (Maquet et al., 2000; Fischer et al., 2002), and 
stage 2 NREM sleep (Walker et al., 2002), have been implicated in consolidation of procedural memories. What factor determines the specificity of a particular sleep phase for the consolidation of the learned information is unclear. Also there is no direct evidence for the mnemonic processes underlying sleep-state consolidation of information at the putative sites of motor memory (for e.g., cerebellum, motor cortex, and basal ganglia).Tracing the link between sleep and motor memory at these sites might provide clues not only to the extent of interaction of the sites of motor memory with sleep physiology (Takakusaki et al., 2004; Cunchillos and De Andres, 1982), but also to a better understanding of sleep disturbances in movement disorders (Larsen and Tandberg, 2001) and the interactions between subcortical, archicortical and neocortical networks of procedural memory consolidation. Whether the latter interactions are dynamically state dependent is another interesting question.

\section{Conclusions}

The results from studies in motor learning and sleep suggest a facilitative role of sleep in selective forms of motor learning. The mechanisms underlying sleep-state consolidation of procedural information remain to be elucidated. Clearly, much remains to be learned on the intriguing role of sleep in motor learning.

\section{Acknowledgements}

I would like to thank Dr. Patricia S. Pohl and the anonymous reviewer for thoughtful comments on the manuscript.

\section{References}

Amzica, F., Neckelmann, D. and Steriade, M. Instrumental conditioning of fast (20- to $50-\mathrm{Hz})$ oscillations in corticothalamic networks. Proc Natl Acad Sci U S A, 1997, 94: 1985-9.
Bliss, T. V. and Lomo, T. Long-lasting potentiation of synaptic transmission in the dentate area of the anaesthetized rabbit following stimulation of the perforant path. J Physiol, 1973, 232: 331-56.

Brashers-Krug, T., Shadmehr, R. and Bizzi, E. Consolidation in human motor memory. Nature, 1996, 382: 252-5.

Buchegger, J., Fritsch, R., Meier-Koll, A. and Riehle, $H$. Does trampolining and anaerobic physical fitness affect sleep? Percept Mot Skills, 1991, 73: 243-52.

Buchegger, J. and Meier-Koll, A. Motor learning and ultradian sleep cycle: an electroencephalographic study of trampoliners. Percept Mot Skills, 1988, 67: 635-45.

Cunchillos, J. D. and De Andres, I. Participation of the cerebellum in the regulation of the sleepwakefulness cycle. Results in cerebellectomized cats. Electroencephalogr Clin Neurophysiol, 1982, 53: 549-58.

Decker, L. R. and Rogers, C. A., Jr. Forced guidance and distribution of practice in sequential information processing. Percept Mot Skills, 1973, 36: 415-9.

Donchin, O., Sawaki, L., Madupu, G., Cohen, L. G. and Shadmehr, R. Mechanisms influencing acquisition and recall of motor memories. J Neurophysiol, 2002, 88: 2114-23.

Doyon, J., Penhune, V. and Ungerleider, L. G. Distinct contribution of the cortico-striatal and cortico-cerebellar systems to motor skill learning. Neuropsychologia, 2003, 41: 252-62.

Fischer, S., Hallschmid, M., Elsner, A. L. and Born, J. Sleep forms memory for finger skills. Proc Natl Acad Sci U S A, 2002, 99: 11987-91.

Forest, G. and Godbout, R. Effects of sleep deprivation on performance and EEG spectral 
analysis in young adults. Brain Cogn, 2000, 43: 195-200.

Fox, P. W., Hershberger, S. L. and Bouchard, T. J., Jr. Genetic and environmental contributions to the acquisition of a motor skill. Nature, 1996, 384: 356-8.

Fuster, J. M. Executive frontal functions. Exp Brain Res, 2000, 133: 66-70.

Georgopoulos, A. P. Neural aspects of cognitive motor control. Curr Opin Neurobiol, 2000, 10: 238-41.

Goode, S. L., Meeuwsen, H. J. and Magill, R. A. Benefits of providing cognitive performance strategies to novice performers learning a complex motor skill. Percept Mot Skills, 1998, 86: $976-8$.

Halgren, E. Firing of human hippocampal units in relation to voluntary movements. Hippocampus, 1991, 1: 153-61.

Halsband, U. and Freund, H. J. Motor learning. Curr Opin Neurobiol, 1993, 3: 940-9.

Hennevin, E., Hars, B., Maho, C. and Bloch, V. Processing of learned information in paradoxical sleep: relevance for memory. Behav Brain Res, 1995, 69: 125-35.

Heyes, C. M. and Foster, C. L. Motor learning by observation: evidence from a serial reaction time task. Q J Exp Psychol A, 2002, 55: 593-607.

Higgins, S. Motor skill acquisition. Phys Ther, 1991, 71: 123-39.

Hikosaka, O., Nakahara, H., Rand, M. K., Sakai, K., Lu, X., Nakamura, K., Miyachi, S. and Doya, K. Parallel neural networks for learning sequential procedures. Trends Neurosci, 1999, 22: 464-71.

Imamizu, H., Miyauchi, S., Tamada, T., Sasaki, Y., Takino, R., Putz, B., Yoshioka, T. and Kawato, M. Human cerebellar activity reflecting an acquired internal model of a new tool. Nature, 2000, 403: 192-5.

Iriki, A., Pavlides, C., Keller, A. and Asanuma, H. Long-term potentiation in the motor cortex. Science, 1989, 245: 1385-7.

Jackson, P. L., Lafleur, M. F., Malouin, F., Richards, C. L. and Doyon, J. Functional cerebral reorganization following motor sequence learning through mental practice with motor imagery. Neuroimage, 2003, 20: 1171-80.

Kandel, E. R. Cellular Mechanisms of Learning and the Biological Basis of Individuality. In: Eric R. Kandel, James H. Schwartz, Thomas M. Jessell (Eds) Principles of Neural Science. McGraw-Hill, 2000: 1247-1277.

Karni, A. The acquisition of perceptual and motor skills: a memory system in the adult human cortex. Brain Res Cogn Brain Res, 1996, 5: 39-48.

Kavanau, J. L. Memory, sleep and the evolution of mechanisms of synaptic efficacy maintenance. Neuroscience, 1997, 79: 7-44.

Kawashima, R., Tajima, N., Yoshida, H., Okita, K., Sasaki, T., Schormann, T., Ogawa, A., Fukuda, H. and Zilles, K. The effect of verbal feedback on motor learning--a PET study. Positron emission tomography. Neuroimage, 2000, 12: 698-706.

Kovac, M. P., Davis, W. J., Matera, E. M. and Croll, R. P. Organization of synaptic inputs to paracerebral feeding command interneurons of Pleurobranchaea californica. I. Excitatory inputs. J Neurophysiol, 1983, 49: 1517-38.

Larsen, J. P. and Tandberg, E. Sleep disorders in patients with Parkinson's disease: epidemiology and management. CNS Drugs, 2001, 15: 267-75.

Laureys, S., Peigneux, P., Phillips, C., Fuchs, S., Degueldre, C., Aerts, J., Del Fiore, G., Petiau, C., Luxen, A., van der Linden, M., Cleeremans, A., Smith, $C$. and Maquet, P. Experience-dependent 
changes in cerebral functional connectivity during human rapid eye movement sleep. Neuroscience, 2001, 105: 521-5.

Lee, T. D., Swanson, L. R. and Hall, A. L. What is repeated in a repetition? Effects of practice conditions on motor skill acquisition. Phys Ther, 1991, 71: 150-6.

Lisberger, S. G. The neural basis for motor learning in the vestibulo-ocular reflex in monkeys. Trends Neurosci, 1988, 11: 147-52.

Lorincz, A. and Buzsaki, G. Two-phase computational model training long-term memories in the entorhinal-hippocampal region. Ann N Y Acad Sci, 2000, 911: 83-111.

Louie, K. and Wilson, M. A. Temporally structured replay of awake hippocampal ensemble activity during rapid eye movement sleep. Neuron, 2001, 29: 145-56.

Maguire, E. A., Burgess, N. and O'Keefe, J. Human spatial navigation: cognitive maps, sexual dimorphism, and neural substrates. Curr Opin Neurobiol, 1999, 9: 171-7.

Maguire, E. A., Frackowiak, R. S. and Frith, C. D. Learning to find your way: a role for the human hippocampal formation. Proc $R$ Soc Lond B Biol Sci, 1996, 263: 1745-50.

Maquet, P. The role of sleep in learning and memory. Science, 2001, 294: 1048-52.

Maquet, P., Laureys, S., Peigneux, P., Fuchs, S., Petiau, C., Phillips, C., Aerts, J., Del Fiore, G., Degueldre, C., Meulemans, T., Luxen, A., Franck, G., Van Der Linden, M., Smith, C. and Cleeremans, A. Experience-dependent changes in cerebral activation during human REM sleep. Nat Neurosci, 2000, 3: 831-6.

Maquet, P., Schwartz, S., Passingham, R. and Frith, C. Sleep-related consolidation of a visuomotor skill: brain mechanisms as assessed by functional magnetic resonance imaging. J Neurosci, 2003, 23: 1432-40.

Marr, D. Simple memory: a theory for archicortex. Philos Trans R Soc Lond B Biol Sci, 1971, 262: 23-81.

McCormick, D. A. and Thompson, R. F. Neuronal responses of the rabbit cerebellum during acquisition and performance of a classically conditioned nictitating membrane-eyelid response. J Neurosci, 1984, 4: 2811-22.

McGlinchey-Berroth, R., Carrillo, M. C., Gabrieli, J. D., Brawn, C. M. and Disterhoft, J. F. Impaired trace eyeblink conditioning in bilateral, medialtemporal lobe amnesia. Behav Neurosci, 1997, 111: 873-82.

Medler, D. A., and Dawson, M.R.W. Using Redundancy to Improve the Performance of Artificial Neural Networks. In: Elio, R. (Eds) Proceedings of theTenth Biennial Conference of the Canadian Society for Computational Studies of Intelligence. Morgan Kauffman, Palo Alto, CA, 1994: 131-38.

Minden, H. A. Effect of forced motor activity on learning. Percept Mot Skills, 1972, 35: 507-13.

Morgan, J. I. and Curran, T. Stimulustranscription coupling in neurons: role of cellular immediate-early genes. Trends Neurosci, 1989, 12: 459-62.

Moyer, J. R., Jr., Deyo, R. A. and Disterhoft, J. F. Hippocampectomy disrupts trace eye-blink conditioning in rabbits. Behav Neurosci, 1990, 104: 243-52.

Nissen, M. J., and Bullemer, P. Attentional requirements of learning: evidence from performance measures. cognit. Psychol., 1987, 19: 1-32.

Nitsche, M. A., Schauenburg, A., Lang, N., Liebetanz, D., Exner, C., Paulus, W. and Tergau, F. Facilitation of implicit motor learning by weak 
transcranial direct current stimulation of the primary motor cortex in the human. J Cogn Neurosci, 2003, 15: 619-26.

Ohno, H., Urushihara, R., Sei, H. and Morita, Y. REM sleep deprivation suppresses acquisition of classical eyeblink conditioning. Sleep, 2002, 25: 877-81.

O'Keefe, J. Place units in the hippocampus of the freely moving rat. Exp Neurol, 1976, 51: 78109.

Pascual-Leone, A., Grafman, J. and Hallett, M. Modulation of cortical motor output maps during development of implicit and explicit knowledge. Science, 1994, 263: 1287-9.

Passingham, R. E. Premotor cortex and preparation for movement. Exp Brain Res, 1988, 70: 590-6.

Petersen, S. E., van Mier, H., Fiez, J. A. and Raichle, M. E. The effects of practice on the functional anatomy of task performance. Proc Natl Acad Sci U S A, 1998, 95: 853-60.

Plihal, W. and Born, J. Effects of early and late nocturnal sleep on priming and spatial memory. Psychophysiology, 1999, 36: 571-82.

Poe, G. R., Nitz, D. A., McNaughton, B. L. and Barnes, C. A. Experience-dependent phasereversal of hippocampal neuron firing during REM sleep. Brain Res, 2000, 855: 176-80.

Qin, Y. L., McNaughton, B. L., Skaggs, W. E. and Barnes, C. A. Memory reprocessing in corticocortical and hippocampocortical neuronal ensembles. Philos Trans $R$ Soc Lond $B$ Biol Sci, 1997, 352: 1525-33.

Rechtschaffen, A., Bergmann, B. M., Everson, C. A., Kushida, C. A. and Gilliland, M. A. Sleep deprivation in the rat: $X$. Integration and discussion of the findings. Sleep, 1989, 12: 6887.
Ribeiro, S., Goyal, V., Mello, C. V. and Pavlides, C. Brain gene expression during REM sleep depends on prior waking experience. Learn Mem, 1999, 6: 500-8.

Sawaki, L., Cohen, L. G., Classen, J., Davis, B. C. and Butefisch, C. M. Enhancement of usedependent plasticity by D-amphetamine. Neurology, 2002, 59: 1262-4.

Schendan, H. E., Searl, M. M., Melrose, R. J. and Stern, C. E. An FMRI study of the role of the medial temporal lobe in implicit and explicit sequence learning. Neuron, 2003, 37: 1013-25.

Schultz, W., Dayan, P. and Montague, P. R. A neural substrate of prediction and reward. Science, 1997, 275: 1593-9.

Shadmehr, R. and Brashers-Krug, T. Functional stages in the formation of human long-term motor memory. J Neurosci, 1997, 17: 409-19.

Shadmehr, R. and Holcomb, H. H. Neural correlates of motor memory consolidation. Science, 1997, 277: 821-5.

Siapas, A. G. and Wilson, M. A. Coordinated interactions between hippocampal ripples and cortical spindles during slow-wave sleep. Neuron, 1998, 21: 1123-8.

Smith, C. Sleep-states and memory processes. Behav Brain Res, 1995, 69: 137-45.

Smith, C. Sleep-states and memory processes in humans: procedural versus declarative memory systems. Sleep Med Rev, 2001, 5: 491-506.

Smith, C. and MacNeill, C. Impaired motor memory for a pursuit rotor task following Stage 2 sleep loss in college students. J Sleep Res, 1994, 3: 206-213.

Squire, L. R. Memory and the hippocampus: a synthesis from findings with rats, monkeys, and humans. Psychol Rev, 1992, 99: 195-231. 
Swindale, N. V. Neurophysiology. Parallel channels and redundant mechanisms in visual cortex. Nature, 1986, 322: 775-6.

Takakusaki, K., Saitoh, K., Harada, H., Okumura, T. and Sakamoto, T. Evidence for a role of basal ganglia in the regulation of rapid eye movement sleep by electrical and chemical stimulation for the pedunculopontine tegmental nucleus and the substantia nigra pars reticulata in decerebrate cats. Neuroscience, 2004, 124: 20720.

Tesche, C. D. and Karhu, J. Interactive processing of sensory input and motor output in the human hippocampus. J Cogn Neurosci, 1999, 11: 424-36.

Thut, G., Schultz, W., Roelcke, U., Nienhusmeier, M., Missimer, J., Maguire, R. P. and Leenders, K. L. Activation of the human brain by monetary reward. Neuroreport, 1997, 8: $1225-8$.

Tinbergen, N. The Study of Instinct, second edition, Oxford University Press, Oxford, 1952.

Todorov, E., Shadmehr, R. and Bizzi, E. Augmented Feedback Presented in a Virtual Environment Accelerates Learning of a Difficult Motor Task. J Mot Behav, 1997, 29: 147-158.

Ungerleider, L. G., Doyon, J. and Karni, A. Imaging brain plasticity during motor skill learning. Neurobiol Learn Mem, 2002, 78: 55364.

Vanderwolf, C. H. Hippocampal electrical activity and voluntary movement in the rat. Electroencephalogr Clin Neurophysiol, 1969, 26: 407-18.

Vanderwolf, C. H. The hippocampus as an olfacto-motor mechanism: were the classical anatomists right after all? Behav Brain Res, 2001, 127: 25-47.
Walker, M. P., Brakefield, T., Morgan, A., Hobson, J. A. and Stickgold, R. Practice with sleep makes perfect: sleep-dependent motor skill learning. Neuron, 2002, 35: 205-11.

Willingham, D. B. A neuropsychological theory of motor skill learning. Psychol Rev, 1998, 105: 558-84.

Wilson, M. A. and McNaughton, B. L. Reactivation of hippocampal ensemble memories during sleep. Science, 1994, 265: 6769.

Wise, S. P. Evolution of Neural Activity During Conditional Motor Learning. In: James $\mathrm{R}$. Bloedel, Timothy J. Ebner and Steven P. Wise (Eds) The Acquisition of Motor Behavior in Vertebrates. The MIT Press, Cambridge, 1996: 261-286.Wise, S. P., Moody, S. L., Blomstrom, K. J. and Mitz, A. R. Changes in motor cortical activity during visuomotor adaptation. Exp Brain Res, 1998, 121: 285-99.

Wood, E. R., Dudchenko, P. A. and Eichenbaum, $\mathrm{H}$. The global record of memory in hippocampal neuronal activity. Nature, 1999, 397: 613-6.

Wood, E. R., Dudchenko, P. A., Robitsek, R. J. and Eichenbaum, H. Hippocampal neurons encode information about different types of memory episodes occurring in the same location. Neuron, 2000, 27: 623-33.

Yaguez, L., Nagel, D., Hoffman, H., Canavan, A. G., Wist, E. and Homberg, V. A mental route to motor learning: improving trajectorial kinematics through imagery training. Behav Brain Res, 1998, 90: 95-106. 
Table 1: Description of Motor Learning Tasks

\begin{tabular}{|c|c|c|}
\hline Task & Description & $\begin{array}{l}\text { Performance Domain and } \\
\text { Measurement Scale }\end{array}$ \\
\hline $\begin{array}{llll}\text { Serial } & \text { Reaction } & \text { Time } & \text { Task } \\
\text { (SRTT) } & & & \\
\end{array}$ & $\begin{array}{l}\text { Subjects face a screen display } \\
\text { with permanent position } \\
\text { markers. Subjects respond to } \\
\text { visual stimuli by pressing a } \\
\text { spatially corresponding key } \\
\text { from a set of controls each } \\
\text { corresponding to a position on } \\
\text { the screen. }\end{array}$ & $\begin{array}{l}\text { Visuo-motor performance } \\
\text { measured as mean reaction } \\
\text { time. }\end{array}$ \\
\hline $\begin{array}{l}\text { Sequential Finger to Thumb } \\
\text { Opposition Task (SFTT) }\end{array}$ & $\begin{array}{l}\text { Subjects are asked to oppose } \\
\text { the fingers (as fast and accurate } \\
\text { as possible, and commonly of } \\
\text { the non-dominant hand) to the } \\
\text { thumb in a specific sequence } \\
\text { without looking at their hand. }\end{array}$ & $\begin{array}{l}\text { Motor performance measured } \\
\text { as the mean number of } \\
\text { correctly completed sequences } \\
\text { during a given test period. }\end{array}$ \\
\hline Pursuit Rotor Task (PRT) & $\begin{array}{l}\text { Subjects are asked to track } \\
\text { (pursue) a moving spot of light } \\
\text { around a rotory pattern. }\end{array}$ & $\begin{array}{l}\text { Visuo-motor performance } \\
\text { measured as mean time on } \\
\text { target. }\end{array}$ \\
\hline Tower of Hanoi Task (TOH) & $\begin{array}{l}\text { Subjects are asked to move an } \\
\text { arrangement of discs } \\
\text { (descending order of size from } \\
\text { the base) from one peg to } \\
\text { another, typically on a three } \\
\text { peg puzzle. Participants are } \\
\text { challenged to use the minimum } \\
\text { number of possible moves such } \\
\text { that no arrangement shall allow } \\
\text { for a disc to be placed over } \\
\text { another smaller counterpart. } \\
\text { Although the subjects are not } \\
\text { made aware of it, for ' } n \text { ' discs, } \\
\text { the puzzle requires } 2^{n}-1 \text { moves } \\
\text { at the least for completion. }\end{array}$ & $\begin{array}{l}\text { Cognitive-motor performance } \\
\text { typically measured by the } \\
\text { number of moves made by the } \\
\text { subject to complete the task. } \\
\text { Additional methods of } \\
\text { performance assessment } \\
\text { include the average latency } \\
\text { between the last disc } \\
\text { placement and the next disc } \\
\text { pick-up as a measure of } \\
\text { planning time for cognitive } \\
\text { processing. }\end{array}$ \\
\hline Trampolining & $\begin{array}{l}\text { Trampolining, since it requires } \\
\text { the acquisition of complex and } \\
\text { unaccustomed motor skills, has } \\
\text { been used as a special case of } \\
\text { motor learning task. Basic } \\
\text { movements such as tuck-, } \\
\text { piked-, straddle-, and twist- } \\
\text { jump as well as various kinds of } \\
\text { somersaults are acquired. }\end{array}$ & $\begin{array}{l}\text { Individual motor performance } \\
\text { is quantified by the ratio of } \\
\text { successfully performed } \\
\text { movements to the number of } \\
\text { trials. }\end{array}$ \\
\hline
\end{tabular}

